\title{
"Last supper with mushroom soup": a case report of amatoxin poisoning
}

\author{
R.N. Das*, S Parajuli, J Jayakumar
}

\section{INTRODUCTION}

Unlike Europeans' pastime of mushroom hunting or lactovegetarian's craze for "organic " food (1), in Himalayan developing nations like Nepal, either poor man's delicacy or hunger, often drives people living in hills to forage for wild mushrooms. In Nepal, unnumbered and medically unpublished small epidemics of mushroom poisoning take a heavy death toll annually. The present case depicts one such incident of accidental death of four youths of a 5-membered family, owing to toxic toadstools.

\section{CASE REPORT}

A 55-year-old woman with the two daughters (23 and 18 -year-old) collected jungle mushrooms and had its soup for dinner along with one 20 -year-old son and a 9 year-old grand-daughter on Tuesday evening at about 8:00 pm. The clinical presentations analyzed retrospectively from the mother and neighbors were as follows: on Wednesday, early morning onwards, the two daughters presented with burning in the throat, stomachache, and vomiting and diarrhea innumerable times. The grand-daughter and son also started complaining of stomach upset at about 10:00 am. The mother began experiencing similar nausea, vomiting, abdominal cramps and bloody diarrhea at noon. On Wednesday afternoon, the village physician diagnosed them cholera and treated them with saline at home. On Thursday morning, the daughters developed jaundice and renal shut down. They died at night within 72 hours post-ingestion, owing to excessive bleeding from venepuncture site, nose, mouth, vagina and rectum that lead to circulatory failure. On Friday morning, neighbors brought the two deceased daughters and the other three family members, who were in a shocked and

\footnotetext{
*To whom correspondence should be addressed: Dr R N Das, associate professor, department of Medicine, Manipal Teaching Hospital, P.O.Box:341, Pokhara, Nepal.

Tel: 0097761 526416/195(Res).

Fax: 0097761527862

Email:das_rabindranath@hotmail.com.
}

comatose state, to Manipal teaching hospital. On examination, all of them had a feeble rapid pulse; unrecordable pressure, cyanosis, jaundice, labored breathing, motor weakness, delirium and confusion (Figure 1). Their serial hemogarm, coagulation profile, liver and renal function tests have been shown (Table 1). The grand-daughter and son died of fulminant hepatic and renal failure on the 2nd and 5th day of hospitalization respectively, despite all conventional treatment with assisted ventilation and dialysis. The post-mortem report revealed massive centrilobular hepatocellular necrosis and proximal convoluted renal tubular fatty degeneration with obstruction owing to haemoglobinuria. The mother recovered, within 4 weeks time, with high dose penicillin, dopamine, dobutamine, blood transfusion, balanced electrolyte infusion, dextrose, silymarin and vitamin $\mathrm{K}$. The principal author and the mother in follow-up, together with help of a toxicologist, identified the poisonous Amanita phalloides when recollected from the same

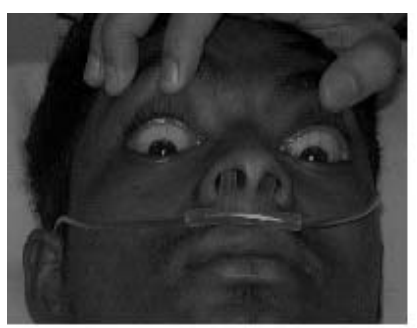

Figure 1. Comatose and deep icterus.

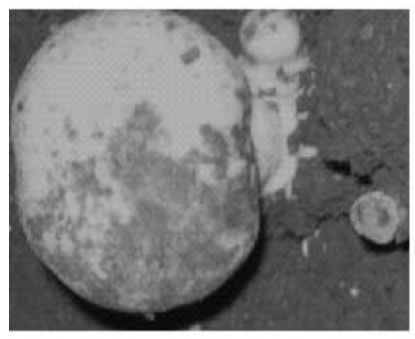

Figure 2. Wild mushroom. 
Table 1: Analysis of laboratory results in all patients

\begin{tabular}{|c|c|c|c|c|c|c|c|c|c|c|c|c|c|c|}
\hline S.N & $\begin{array}{c}\text { Age (1) } \\
\text { /Sex }\end{array}$ & Blood sugar (2) & \multicolumn{2}{|c|}{$\begin{array}{c}\text { Urea/creatinine } \\
\text { (2) }\end{array}$} & \multicolumn{2}{|c|}{$\mathrm{Tb} / \mathrm{Db}(2)$} & \multicolumn{2}{|c|}{ ASL.ALT (3) } & \multicolumn{2}{|c|}{$\overline{\text { PT (6) }}$} & \multicolumn{2}{|c|}{$\mathrm{Na}^{+} / \mathrm{K}^{+}$(4) } & \multicolumn{2}{|c|}{$\mathrm{Hb}(5)$} \\
\hline $1^{\mathrm{st}}$ & $10 / \mathrm{F}$ & 34 & $36 / 2.5$ & & $4.4 / 2.9$ & & $7350 / 7600$ & & 120 & & $130 / 5.9$ & & 10.8 & \\
\hline $2^{\text {nd }}$ & $20 / \mathrm{M}$ & 60 & $44 / 2.9$ & $96 / 5.9$ & $5.5 / 3.4$ & $8.2 / 6.6$ & $1110 / 800$ & $3510 / 3750$ & 67 & 180 & $128 / 6.2$ & $122 / 6.8$ & 12.2 & 11.8 \\
\hline $3^{\text {rd }}$ & $55 / \mathrm{F}$ & 70 & $57 / 1.7$ & $14 / 0.7$ & $2.5 / 1.7$ & $2.0 / 1.1$ & $7815 / 3600$ & $490 / 1210$ & 45 & 22 & $132 / 4.5$ & $138 / 4.1$ & 9.8 & 11.6 \\
\hline Day* & & 1 & $\overline{1}$ & 5 & 1 & 5 & $\overline{1}$ & 5 & 1 & 5 & 1 & 5 & $\overline{1}$ & 5 \\
\hline
\end{tabular}

NB: *Day of hospital admission $\left(1^{\text {st }} \& 5^{\text {th }}\right.$ day). Daily routine investigations were done. $1^{\text {st }}$ patient died on $2^{\text {nd }}$ day morning. So no tests were done afterwards. $2^{\text {nd }}$ patient died on $5^{\text {th }}$ day evening. (1) age in years, (2) urea,creatinine, blood sugar, total bilirubin (Tb) and direct bilirubin $(\mathrm{Db})$ in $\mathrm{mg} \%$, (3) serum transaminases (AST/ALT) in IU/L, (4) electrolytes in $\mathrm{mEq} / \mathrm{L}$, (5) haemoglobin(Hb) in gm\% and (6) prothrombin time (PT) in seconds.

spot and compared the resemblance from the picture book," Poisonous Plants - a colorful field guide" (Figure 2) (2).

\section{DISCUSSION}

Here we present the first ever reported case of amanita poisoning in mid-western region of Nepal in medical literature. There are many such unaccounted cases of fatal mushroom poisoning (mycetismus) which occur in Nepal annually, owing to misidentification of edible mushrooms especially during its fruiting stage in spring and fall. It is difficult, even for an expert mycologist, to visually differentiate the edible one from a toxic toadstool. Although over 5000 varieties of mushrooms are present, only a 100 are toxic (3). The poisonous mushrooms cannot be detoxified by cooking, freezing or by other means. The majority of toxic mushrooms cause early onset, self-limiting gastroenteritis due to unidentified gastrointestinal irritants while a few are fatal, resulting from late onset, amanitin or gyromitrin type protoplasmic toxins (4).

In Nepal, A.muscaria and A. phalloides are the two main species found. The former produces a toxic alkaloid, ibotenic acid, which has a rapid onset muscarinic effect (dizziness, muscular jeking ,staggering, confusion and coma) while the later produces a thermostable nitrogenous cyclic octapeptide, amanitine or amatoxin (alpha and beta) which selectively inhibits the nuclear RNA polymerase II, resulting in hepatic and renal cellular derangement. Besides producing thermolabile hemolytic glycoside, amanita hemolysin, another putative toxin, phalloidin, also causes hepatocellular damage. In amanita poisoning, the first phase starts with sudden severe gastrointestinal symptoms 8-10 hours post ingestion, followed by a temporary second phase of apparent remission of abdominal symptoms but overt features of hepatic and renal failure, as evidenced here in the postmortem report. In the final and third phase, death results from coagulopathy (epistaxis, hematuria, melena and hematemesis), encephalopathy (muscular twitching, excitement, delirium, coma, convulsion) and rarely cardiomyopathy (5).

The symptomatology varies with individual susceptibility, even within the same individual on different occasions, in addition to other factors i.e., amount, variety, age, geographical location and premorbid hepatic and renal conditions. The mother survived while all the others died, though they had soup at the same time. The plausible explanation is that the mother received the least share of the soup after serving the it to the rest. The two daughters and the grand daughter had died earlier to the son, possibly owing to lesser capacity of hepatic enzymes in the female sex to metabolize amatoxin.

There was no facility to do high performance liquid chromatography (HPLC) or radioimmunoassay (RIA) for detection of amatoxin from plasma, feces, urine or vomitus. The progressive deterioration of hepatic, renal and coagulation function in the 1st and 2nd patients and improvement in the 3rd patient had been reflected in laboratory tests shown above.

The mother received benzyl penicillin 1800000 units per day, which was supposed to displace amatoxin from plasma protein binding site, increase renal excretion and inhibit hepatocyte penetration. Silymarin (MicroLab, Pharma, India) $420 \mathrm{mg}$ a day, was given empirically in addition to conventional treatment. Silymarin, a potent antioxidant was known to prevent hepatocyte membrane lipid peroxidation, free radical damage and blockage of $\alpha$-amatoxin uptake (6).

In Nepal, neither thioctic acid was available nor was liver transplant possible. Whereas, in Europe, early hospitalization, rapid diagnosis and aggressive management with charcoal hemoperfusion, thioctic acid, plasma exchange, extracorporeal liver assist device (ELAD) or orthotopic liver transplantation have shown to reduce mortality to $10 \%$ whereas 60 -hour 
delay increases it to $50-90 \%$ (7).

The mortality is higher in children $(>50 \%)$ as compared to adults (20-30\%). The fatality depends on amount and particular species consumed. If unattended, death ensues in 6-8 days in adults and as early as 4-6 days in children (8).

Every physician should consider amanita toxicity in the differential diagnosis of acute gastroenteritis and renal failure, especially in high prevalent regions. The essential steps of management would be early hospitalization, charcoal gastric lavage conventional fluid, dextrose, penicillin and silymarin therapy with hepatorenal support. Aiming at primary prevention, the government should hasten to establish regional toxicology centres which would impart public education and identify toxic toadstool, in order to reduce the mortality.

\section{ACKNOWLEDGEMENT}

The principal author Dr. R.N. Das is indebted to Prof.Shyam Lohani, Director, Institute of Toxicology, Katmandu, Nepal for identification of the poisonous Amanita. The authors are also grateful to Prof. J.S. Nagra, Dean and Director, MCOMS and MTH for his support in writing this article.

\section{REFRENCES}

1. Berger KJ, Guss DA. Mycotoxins revisited: Part II. J Emerg Med 2005 Feb; 28(2): 175-83.

2. Woodward L. Poisonous Plants - a colourful field guide. London: David \& Charles (publishers), London; 1985.

3. Diaz JH. Syndromic diagnosis and management of confirmed mushroom poisonings. Crit Care Med 2005 Feb; 33(2):427-36.

4. Saviuc P, Flesch F. Acute higher fungi mushroom poisoning and its treatment. Presse Med 2003 Sep 20; 32(30):1427-35.

5. Bonnet MS, Basson PW. The toxicology of Amanita virosa: the destroying angel. Homeopathy 2004 Oct; 93(4):216-20.

6. Koppel, C. Clinical symptomatology and management of mushroom poisoning. Toxicon 1993, 31; 1513-1540.

7. Gavornik P. Prevention and treatment of mushroom poisoning. Vnitr Lek. 1999 Mar; 45(3):193-6.

8. Karlson-Stiber C, Persson H. Cytotoxic fungi - an overview. Toxicon 2003 Sep 15; 42(4): 339-49.

R. N. Das, MBBS, MD, MRCP (UK), FRCP (London) is presently working as an associate professor in the department of Medicine, Manipal Teaching Hospital, Pokhara, Nepal. He graduated from the famous and oldest medical college under Calcutta University. He obtained his post-graduate degree from a premier institute in India, PGIMER; Chandigarh. He has a brilliant academic record and more than 17 years of work experience in different branches of clinical medicine, especially tropical and infectious diseases in several hospitals in India, Middle East, United Kingdom and Nepal. He has more than 50 publications in scientific journals at home and abroad. He is an astute clinician, a popular teacher and an honest researcher. He lays stress on clinical diagnosis and abhors unnecessary sophisticated investigations. He loves to be an internal medicine specialist. His main subject of interest is tropical medicine. Besides his own medical field, Dr. Das also takes keen interest in history, comparative literature and religion. He is humorous, a good orator and a prolific writer. 